\title{
4 Visions of vision: governments, companies, activists and how they deal with visibility, transparency and surveillance - Jakob Zeijl
}

\subsection{Introduction}

Seeing is knowing. But seeing is not just seeing. Throughout the ages, humanity has constructed vision in many different ways. Therefore, it is imperative to take a closer look at the construction of vision, especially in the digital age, which greatly expanded our abilities to see and, particularly, oversee. Foucault (1995) argued that seeing is cleaning; through increased visibility the Jacobins tried to sanitize the dark spaces of royal privilege and religious superstition. Their ideas, however, became vampirized and were turned into governmental systems of control, observation and regulation. Echoing the Jacobins, we demand transparency to extend our control over business and politics. To prevent us from making the same mistakes again, we should examine how vision was constructed, how it can be constructed, and what possible dangers might arise.

The term surveillance derives from the Latin word super, meaning "over" or "above", and vigilare, meaning "to watch" or "to be vigilant". It generally describes watching over a person or a group. Transparency is of Latin origin and denotes perviousness to light (Hood, \& Heald, 2006, p. 4). It is a composite of the words trans, translated as "through" or "across", and parere, meaning "to appear", "to come in sight". Making something transparent is to move it from the realm of opacity into light, to make it visible. What is more, the preposition trans suggests that more than mere appearance is made visible; light is passed through appearance and renders the core, the essence visible. Therefore, transparency is seen as a precondition for a free and unaltered glimpse at reality (Landkammer, 2010, p. 239). Both terms gained prominence in recent years, especially the 
demand for transparency has acquired widespread support. Transparency is demanded because it is implicitly believed that something visible can offer no resistance and can easily be changed (Nietzsche, 1881/2007, §444). In that sense, transparency and surveillance share certain characteristics: both are attempts at changing behavior by increasing the visibility of persons and/or companies.

This paper studies various ways of conceptualizing and dealing with visibility, especially concerning transparency and surveillance. To put it differently, the overall research question is to find out how activists, politicians and companies construct transparency. By answering that question this paper intends to show that there are structural differences in approaches towards transparency between on the one hand artists and activists and on the other hand companies and politicians. However, also activists differ from each other in how they approach transparency. This is important to realize because transparency is more often invoked than defined. Therefore, it is worthwhile to investigate possible frameworks of transparency, their advantages and their disadvantages. Moreover, since transparency and surveillance have a similar aim, there is an overlap between them that needs to be scrutinized. The method employed is a qualitative content analysis of literature.

Firstly, this paper elaborates on the logic of surveillance. Secondly, sustainability reports and the framing of transparency in the current Obama administration are used as case studies of transparency in economics and politics. Thirdly, the way transparency is enacted by WikiLeaks is investigated. Special attention is paid to WikiLeaks' decentralized, inclusive and non-hierarchical structure. Fourthly, this paper shows how WikiLeaks' concept of non-hierarchical, decentralized and inclusive transparency could be adopted in everyday life by referring to Steve Mann's concept of "sousveillance". However, the decentralization resulting from both, Wikileaks 
and Mann, is criticized by many. This paper focusses on two outspoken critics of enhanced transparency, Han and Bessire, and elaborates on their arguments. Fifthly, the anarchist Camover intervention is assessed and linked to Han's and Bessire's argument for more opacity. Lastly, all projects are compared and discussed. It is argued that the examined attempts at transparency enacted by governments and companies reflect and consolidate existing power relations and are therefore not likely to expose misdemeanor or lead to significant changes. WikiLeaks and Mann construct transparency radically different and show potential alternatives that could greatly affect existing power relations. Nevertheless, these alternatives house considerable dangers and do not by default empower us.

\subsection{The Mono-Directional Logic of Surveillance}

The academic landmark of surveillance is Foucault's account of panopticism. The Utilitarian Bentham developed a prison blueprint that greatly differed from the "old regime" monarchical system of incarceration. Since the judiciary of monarchies could only arrest a derisory proportion of criminals, their punishment was turned into a public spectacle in order to deter others. Theorists of the 18th century argued that "such a form of power was too costly in proportion to its results" (Foucault, 1980, p. 155) and devised a new penal system, the one we know today. Bentham's model of the Panopticon is a central tower placed in the middle of a circular building. From this vantage point, it was possible to observe every cell and every inmate. Since the windows of the central tower were blackened, the inmates did not know whether they were observed at the moment or not.

Nevertheless, the fear of possible observation prompts the inmates to adjust their behavior accordingly. Through internalization of the disciplinary gaze, inmates are made to observe themselves, something that Foucault calls "[a] superb formula: power exercised continuously and for what turns out to be a 
minimal cost" (pp. 155). The tower is the origin of a mono-directional gaze: its inhabitants administer the gaze and everything is transparent for them, whereas the inmates, the objects of the gaze, cannot gaze back.

Surveillance, already by its etymological meaning, can only be practiced by the superior, by those in power. Surveillance is the prerogative of official institutions and indicative of a power- and an information asymmetry. Ganascia (2009) argues that "surveillance characterizes situations where a watcher is positioned above the watched" (p. 2). In this context, above refers to a positional as well as a social viewpoint. The watcher is able to collect and use information whereas the watched often do not know who watches them and are consequently dominated by the watchers. Furthermore, Ganascia points out that the logic of surveillance is not only limited to information access but also to information dissemination which is controlled by a central organization imposing censure (p. 2). Mechanisms of surveillance are inherently undemocratic, according to Mann (2013a). He argues that "surveillance is the veillance [sic] of centralized data repository" (18:40), meaning that only one party is allowed to gather information and access these. Surveillance is mono-directional, meaning that not only the overseeing gaze but also information dissemination is a oneway road. The empowered overseer administers the gaze and decides which information is disseminated, whereas the disempowered seen cannot gaze back nor can they enter the centralized data repository.

One intuitively thinks transparency to be good, surveillance to be bad and both, therefore, to be miles apart. Interestingly enough, the logic of surveillance can be found in many attempts to establish transparency, as the next section argues. 


\subsection{The Hyperreality of Transparency}

Companies increasingly publish sustainability reports that should inform about their social, economic and environmental impact. This is done for purely altruistic motives, such as managing change towards a sustainable global economy, but it is also a practical necessity to disclose reliable data in order to attract potential shareholders and to enhance trust of the already existing ones. The Global Reporting Initiative (GRI) is an international, nonprofit organization that aims at making sustainability reporting a standard procedure for all companies and organizations. The GRI has developed and introduced a standardized Sustainability Reporting Framework that is used around the world. Their declared vision is "[a] sustainable global economy where organizations manage their economic, environmental, social and governance performance and impacts responsibly, and report transparently" (GRI, 2011, p. 2). The GRI assesses sustainability reports according to its standardized framework and grades them.

Boiral (2013) analyzed 23 sustainability reports from the energy and mining sector from the year 2007 which received top grades from the GRI (A or $A+)$ in order to find out whether the disclosed information are correct and reliable. He concluded that the sustainability reports were severely disconnected "from the realities of the negative impacts of business activities, due to a lack of transparency in reporting" (p. 1051). While the GRI states that "[a] sustainability report is the key platform for communicating sustainability performance and impacts - whether positive or negative" (GRI, no date, 'What is Sustainability Reporting?', my italics), 90 per cent of significant negative events "were either omitted from the sustainability report or addressed in a very incomplete and non-transparent fashion" (Boiral, 2013, p. 1051). The use of a standardized framework has undoubtedly increased the rigor of sustainability reporting. Nevertheless, their reliability and transparency is a matter of debate. While many authors 
have criticized their often superficial nature and their reflection of business interests, rather than a genuine interest in accountability and transparency (Gray, 1992; Unerman, Bebbington, \& O'Dwyer, 2007; Moneva, Archel, \& Correa, 2006), Boiral even goes so far to argue that these sustainability reports are mere "simulacra". Simulacrum is a term of Baudrillard's media philosophy concerned with the relationship between signs of the real and the real. According to Baudrillard, our representations of reality are completely disconnected to reality itself. Deprived of reality, there are only simulacra that precede and determine the real. The artificial is not real but constitutes reality; reality has given way to hyperreality (Baudrillard, 1994). This not only calls into question the transparency in sustainability reporting, it also confirms "that sustainability reports can be viewed as simulacra that camouflage real sustainable-development problems, presenting an idealized version of company situations" (Boiral, 2013, p. 1061).

Boiral's analysis indicates how the logic of surveillance penetrates attempts to establish transparency. The companies greatly benefit from an information asymmetry since they are free to decide what to disclose and what to censor. They are the guardians of a centralized data repository and they provide an unequal access to it. Governments, stakeholders and environmentalists are placed at the receiving end of the one-way road of information dissemination and have to trust in the information they are given.

Many attempts at transparency are characterized by the logic of surveillance, that is, transparency in which the hierarchy of gazes remains intact: the empowered seer decides what the disempowered seen gets to see. Institutions whose transparency is demanded are asked to disclose information themselves. In the case of sensitive information, this is akin to asking a criminal to help investigating his own crimes. For example, thousands of documents that recorded shameful acts in the last years of the 
British Empire have been destroyed or kept in a secret British Foreign Office Archive in clear breach of legal obligations to disclose them in order to prevent them from "falling into the hands of post-independence governments" (Cobain, Bowcott, \& Norton-Taylor, 2012, paragraph 1). And while this might be an extreme example, it is nevertheless indicative of panoptic transparency. The seer decides what is made transparent, how it is made transparent, indeed, the seer is even defining the very term "transparency". Investigating the framing of transparency in the current Obama administration, Herrmann points out that WikiLeaks is solely referred to as "disclosure" rather than "transparency". She further hints that

[a]n explanation would be that the administration has appropriated the term 'transparency' for itself and seems to have clear conceptions of transparency and its positive correlation with accountability, trust and good governance. . . WikiLeaks is definitely not seen in the light of transparency and the service of the good; it is criminalized and depicted as a threat to national security (Herrmann, 2013, p. 139).

And while Obama stated in a memorandum that "[m]y Administration is committed to creating an unprecedented level of openness in Government. We will work together to ensure public trust and establish a system of transparency" (Obama, 2009, paragraph 1), the reality looks different. An analysis by Associated Press, investigating the accessibility of information under the Freedom Of Information Act in 2014, showed that on the one hand public demand for information is at a record high. On the other hand, however, government secrecy is as well. More often than ever before did the Obama administration censor government files or deny access completely. Moreover, the analysis highlighted that "in about a third of instances, the government conceded that initial decisions to withhold or censor documents 
were 'improper under the law - but only when it was challenged'" (Wemple, 2012, paragraph 3).

The logic of surveillance is one of hierarchy, of exclusivity, and of unequal information access and dissemination. This logic spilled over into the construction of transparency. Shaped by the logic of surveillance, transparency becomes the site for the reproduction of the logic of surveillance. This, however, is not the only way vision and transparency can be constructed. In recent years, an increasing number of activists engaged with the issue of surveillance and transparency. All of them have dealt with visibility in a different way and all of them have constructed vision differently.

\subsection{Wikileaks: The New Framing of Transparency and the Intricacies of Dating}

Whether Wikileaks has been successful or not, remains open. Fenster (2012) analyzed the effects of WikiLeaks and concludes that neither was a political movement of any significant size formed, nor was there a "significant or even discernible movement to change existing military engagements or foreign policy in the period following the WikiLeaks disclosures" (p. 801). Nevertheless, WikiLeaks aroused a considerable amount of controversy: Flanagan, the former advisor to the Canadian Prime Minister Harper, Kuhner, a Washington Times Columnist, Liddy, a former White House Advisor, and many more demanded Assange to be assassinated (WikiLeaks, 2012). Mao famously said that being attacked by the enemy is a good thing, because it shows that one has drawn a clear line of demarcation between oneself and the enemy. While Mao is a questionable authority in political matters, the fact that politicians responded so violently to WikiLeaks indicates the amount of threat it poses. In a panel discussion with Žižek and Goodman, Assange argues that censorship is a good sign because it shows that society is not 
yet totally "fiscalised". Power in a totally hegemonic position is silent and as responsive as a human who accidentally steps on an ant (Žižek, Assange, \& Goodman, 2012, 37:06). If WikiLeaks' impact was negligible, how are the extremely harsh and hostile reactions of politicians, companies and even activists to be explained?

Firstly, WikiLeaks stands in stark contrast to panoptic transparency and explicitly disregards the official framing of transparency. According to Žižek, it is the ultimate show of power of a ruling ideology to allow for criticism. Referring to the abundance of anti-capitalist sentiment, he goes on to criticize that "there is a catch: what isn't questioned in these critiques is the democratic-liberal framing of the fight against these excesses [corrupt bankers, sweatshops]" (Žižek, 2011, p. 2). Criticism is allowed because it is framed by its own object. WikiLeaks' gaze was directed at big companies and politics which is not anything new or surprising but how it staged the gaze marks its difference to traditional agents of transparency. Giri (2010) states that WikiLeaks carries a tremendous radical political charge because "they challenged power by challenging the normal channels of challenging power" (paragraph 6). In liberal regimes -or regimes that want to appear so- there is a certain way, legitimized by the authorities, which one is allowed to go about challenging it. For example, if one would like to access data held by a federal organization one can invoke the Freedom Of Information Act or even go to court if the government insists on nondisclosure. These ways, however, are governmentally prescribed acts of resistance. In the very act of resisting, one sticks to, and in certain way reinforces, the authority one wants to challenge. By disrespecting the usual channels of information flow, such as governments, courts, civil bodies, and (initially) corporate media, WikiLeaks has changed the rules of the game.

Secondly, in a short talk experimental psychologist and linguist Pinker (2011) solves the puzzle of why humans prefer to use innuendos rather than 
direct overtures; for example asking whether one would like to come up for a cup of coffee rather than directly asking for sex. Pinker introduces a concept that economists and logicians call Mutual Knowledge. Its opposite is Individual Knowledge and refers to a situation in which $A$ knows $X$ and $B$ knows X. Mutual Knowledge denotes a situation in which A knows $X, B$ knows $X, A$ knows that $B$ knows $X, B$ knows that $A$ knows $X, A$ knows that $B$ knows that $A$ knows $X, B$ knows that $A$ knows that $B$ knows $X$, ad infinitum. Using innuendos avoids the creation of Mutual Knowledge and can avert embarrassment. Mutual Knowledge not only has profound consequences for dating but also for politics. Pinker claims that revolutions are often triggered as direct result of Mutual Knowledge. Being home alone and despising a dictator, one feels insecure and one does not know whether one's own grudge is held by others. When, however, a crowd gathers in a square "everyone knows that everyone else knows that everyone else knows that the dictator is loathed" (8:37), which gives them the collective power to challenge her/him.

WikiLeaks can be seen in that light as well. Even though WikiLeaks' disclosures might have not revealed anything surprisingly new (Žižek, 2011, p. 3; Fenster, 2012, p. 777), it has given irrefutable evidence of misdemeanor and has therefore changed our status of knowledge from Individual Knowledge to Mutual Knowledge. Accusations that previously had only circulated in specific milieus, that had been shunned and kept quiet, became Mutual Knowledge. And albeit Mutual Knowledge is not a sufficient condition for change, it is a necessary one.

Thirdly, challenging the frame advances participation. McLuhan remarked that "connected spaces and situations exclude participation whereas discontinuity affords room for involvement" (McLuhan, \& Zingrone, 1997, p. 341). WikiLeaks does not present a cleat-cut narrative and formal harmony. The leaks disclose information from different countries and deal 
with different topics. WikiLeaks is constantly disclosing new documents, the whole page is in constant flux. And it is this state of becoming that invites participation. WikiLeaks is an open-end project and although people know that a state of perfect transparency will never be reached, they still aim for it. Anyone can add documents without fearing to destroy the meaning of the whole. This discontinuous and fragmented way of disclosing data is contrasted by the publication of sustainability reports. These reports present a straight and continuous narrative of a company's impact on everyday life. This narrative is meant to present harmony, at the expense of real problems. Therefore, data-selection is selective and information that will not contribute to a positive company image is omitted. Including that information in a sustainability report could upset its balance. The company decides what is published and contributions of outsiders, such as environmentalists, are not taken into consideration.

Fourthly, also the creation of Mutual Knowledge advances participation because more and more people on both sides get involved. Unfounded assumptions hardly lead to consequences. Facts, however, act like stones thrown into a sea: they create circles far bigger than the stone itself. After the release of the State Department cables in 2010, several web services stopped collaborating with WikiLeaks. And while Roberts might be correct in claiming that this was due to economic considerations rather than direct political pressure (Roberts, 2012, p. 7), it is indicative of something else, namely of spillover effects and internal dynamics. The leaks caused a reaction from economic companies which in turn caused a reaction from the hacker collective Anonymous. People who previously had nothing to do with WikiLeaks were drawn into the struggle around it.

The fundamental inequality between observer and observed, exemplified in the sustainability reports, is at least partially challenged by WikiLeaks. Making incidents in Iraq, Guantanamo Bay or Kenya transparent, 
is moving towards more equality since every regular citizen has the ability to observe the powerful. While this does not erase existing power relations and neither exalts the citizen from her/his role as object of the gaze, it gives the citizen a tool to return the gaze and become a master of the gaze, too. The traditional demand for transparency relies on the dissemination of information through privileged and powerful institutions. The flow of information is therefore mono-directional: only approved information is released. WikiLeaks' decentralized way of spreading information presents something entirely different, something that relies to a great extent on the new possibilities the Internet offers. And while Roberts (2012) and Fenster (2012) are certainly correct in their analysis that the Internet alone will not be enough to establish transparency and induce change, WikiLeaks has made an important point. The interconnectedness of the Internet allows easy bulk data sharing and a reversal of the roles of seer and seen. Most attempts at transparency that rely on the Internet adopt the traditional centralized structure; they try to do with the new what already did not work with the old. While sustainability reports and e-government initiatives rely on the Internet to disseminate information, the origin of that information is a centralized entity which has the possibility to impose censorship. Thus, the revolutionary potential of WikiLeaks lies in its structure rather than in the content of the leaks themselves. WikiLeaks has made the frame apparent under which transparency is allowed to be pursued. WikiLeaks' transparency stands in stark contrast to the panoptic transparency of governments and companies.

While WikiLeaks was called drastic by many, its concept of decentralized, non-hierarchical and inclusive transparency has been put to the extreme by others, most notably by Canadian inventor and researcher Steve Mann. The next part decribes how the logic of Wikileaks can be - and already is - applied on a day to day basis by elaborating on Mann's ideas. 


\subsection{Equiveillance and its Dangers}

Steve Mann is an outspoken opponent of surveillance whose suggestion for challenging surveillance is diametrically opposed to logic of surveillance. He believes the solution is to be found in wearable, wireless computers. In our modern technological society, anyone can take pictures or record persons and events, and distribute the information all over the world. Mann has coined the term "sousveillance", which denotes a state of affairs in which everyone is watching everyone and everyone has equal access to information about others. Whereas surveillance denotes a situation in which watch is kept from above, sousveillance refers to watch kept from below. As prime example of sousveillance, Mann (2003) refers to the videotape showing police officers beating Rodney King (p. 333). He points out that there is a fundamental inequality in surveillance, namely that ordinary citizens are not allowed to take pictures, for example in governmental buildings and shops whereas surveillance cameras are installed everywhere in these premises. These asymmetric photography/video policies reflect the unbalanced power relationship of the Panopticon. Mann pioneered inventions like the Eye Glass, glasses that can record and display video material. His Eye Glass constantly records and Mann even uploaded a live stream to the Internet (Mann, 2013b, paragraph 9). These inventions, Mann argues, will have a dual effect. Firstly, they will alter the nature of surveillance. Surveillance cameras are placed at vantage points and are therefore more privacy invasive than the Eye Glass, which is placed on eye-level. Secondly, these inventions impact on the hierarchy of surveillance. Whereas so far surveillance was a restricted praxis of authorities, wearable computing devices allow the large scale implementation of sousveillance. Taken 
together, these two changes are supposed to bring down "the camera or other means of observation to a human level" (Mann, 2012, paragraph 15).

In a talk, Mann highlights the benefits of sousveillance by comparing two stories. In 2005, policemen shot and killed an alleged terrorist in the London Underground. It turned out that the police had made a mistake and that they had killed an electrician. This incident was recorded by four individual CCTV systems, which the police seized and claimed to be blank. However, some of the Underground's employees had a look at the tapes before the seizure and stated that there was content on them. In Canada in 2013, a boy was found standing in an empty streetcar with a knife. Police surrounded the boy remaining at a safe distance and urged him to drop the knife. The boy did not move, so an officer shot him three times. The boy fell to the ground and the officer shot him another six times. While the British officers were acquitted, the Canadian officer was accused of murder. Mann argues that the fundamental difference between the two cases resulting in the different legal treatment is to be found in the presence of sousveillance in the latter case. The incident was not only recorded by the CCTV cameras in the streetcar and by the police, but also by several bystanders. Mann argues that the bystanders made the difference: were the incident recorded only by the police and the streetcar CCTV, the police might have seized the CCTV tapes and maintained their monopoly on information. The possible result of that can be found in the London case. However, the public filming that incident was practicing sousveillance and its open nature and crowdsourcing tactics brought the matter to public (and later jurisdictional) attention. Thus, sousveillance is the complementary side of surveillance. It can counter the inherent asymmetry in surveillance and establish an equality of vision (Mann, 2013a), an "equiveillance" (Ganascia, 2009, p. 1).

Mann advocates the abolishment of the monopoly on information acquisition and dissemination that official institutions have had until now. He 
aims at an eradication of the information asymmetry by making himself and everything around him completely transparent. Through a radical decentralization of the official channels of information, Mann wants to challenge the mono-directionality of information. Moreover, he argues, sousveillance is a non-hierarchical system, since everyone has the right to record and access the recordings. It is, however, exactly this decentralization and poly-centricity, which has received harsh criticism.

Most critics of decentralized transparency are united in their belief that there is no difference between surveillance and transparency. According to them, it is more appropriate to speak of a surveillance/transparency complex. They fear that a world of multilateral visibility will greatly expand the Panopticon. In his book Transparency Society, the cultural theorist and philosopher Byung-Chul Han argues that we are witnessing the emergence of a new Panopticon. This new Panopticon is "aperspectival", because there is no center of surveillance. "The distinction between center and periphery, constitutive of Bentham's Panopticon, disappears completely" (Han, 2012, pp. 74, all quotes are by Zeijl). According to Han, aperspectival surveillance is much more efficient than perspectival surveillance, for it is now possible to be screened not only from every direction but also from everybody ( $p .75$ ). While inmates of Bentham's Panopticon are aware of the presence of an authority, inmates of the new Panopticon think to be free and voluntarily surveil and expose themselves. The emergence of a total Panopticon is accompanied by a waning of trust and morality, as Han argues. Since the call for transparency is echoed most often at times of disappearing trust, the "transparency society is a society of distrust and suspicion which relies on transparency due to disappearing trust" (p. 79). Instead of morality and trust, transparency becomes the new social imperative and the distinction between public and private sphere which governed our lives for roughly 300 years is obliterated. 
This line of argumentation is echoed by Bessire, who investigates what the discourse on transparency hides and elaborates on the common assumption that information asymmetries lead to adverse selection and moral hazards. Transparency, used in this context, is supposed to prevent agents from adopting opportunistic behavior. Therefore, transparency is merely a different but positively connoted term for panopticism. Whereas her essay focusses on elaborating solutions for the world of business, her main argument against transparency is so broad that it relates to any other aspect of life in connection with transparency. Bessire's argument can be summarized as follows:

1. Economic interest, or any form of self interest, is tamed by surveillance mechanisms, which are being presented as enhancements of transparency.

2. Surveillance mechanisms reduce individuals to inmates of a virtual prison and render them unfree.

3. Without freedom, there is neither responsibility nor ethics, and one yields to determinism.

Therefore,

4. Transparency will not lead to a moralization of (business) life but to its opposite, generalized amorality (Bessire, 2005, pp. 430).

Bessire's argument is valid, that is, the conclusion is a logical and necessary inference of its premises. A convincing argument, however, not only has to be valid but also sound, that is, being valid and having premises that are actually true - and Bessire's premises are not without flaws.

Premise 2, for example, is a rather determinist reading of Foucault, which trivializes the original argument. Foucault acknowledges that disciplinary power controls and defines the human subject, but it never fully 
achieves what it sets out to do. The internalization of disciplinary power is highly individualized and can have adverse effects. Instead of producing docile bodies, prisons can work as criminal factories for they convince inmates that they are indeed all the things the system tells them to be, such as deviant, lazy and/or evil. "In this respect, power is successful in 'writing' people, but the effects are not what was intended" (Danaher, Schirato, \& Webb, 2000, p. 80).

Concerning premise 3, it seems that Bessire's own ethical bias from which her criticism is launched is not without contradiction. She claims that a loss of freedom inevitably results in determinism. Thus, Bessire drives a wedge between freedom and determinism, claiming both to be diametrically opposed and incompatible. However, as Kurtulmuş points out, there is a problem with that view: suppose some of our actions were not determined by character, education or, for that matter, biopower. These undetermined actions would be merely random events rather than free actions of free individuals. Or, to put it differently: in how far can an action that is undetermined by your character, desires or beliefs be said to be truly yours (Kurtulmuş, 2014, p. 2) ${ }^{1}$ ? Thus, there seems to be a dilemma: if determinism is true, our actions are unfree but if Bessire's conception of freedom is true, our actions are random events and therefore not free either.

In summary, it might be true that the current discussion on transparency indeed shares similarities with Foucault's panopticism. However, Bessire's rather negative evaluation misses the point. A transparent society does not by default abolish the freedom of its individuals because disciplinary power, in and of itself, is not constitutive of subjectivity

\footnotetext{
${ }^{1}$ It is not within the scope of this paper to try to solve this dilemma. Interested readers find a discussion of Compatibilism in Rachels and Rachels (2012) which offers a way out. Nevertheless, this way is disputed.
} 
and resistance is always possible. Secondly, a Manichean distinction between freedom and determinism is an oversimplification. Bessire understands "free" to mean "uncaused". However, an uncaused action is merely random and hardly counts as a conscious, reasoned action. In that case, it does not make much sense to speak of them as free actions.

Han's book Transparency Society is a pamphlet and has therefore to be enjoyed with care. His style of writing resembles Nietzsche's in his use of aphorisms, short and suggestive sentences, and eloquent style. Han, however, proves to be more hammer than philosopher, since he occasionally is oblivious to the reality of our world. Criticizing Rousseau's dislike of theatre as place of deception, disguise and mere appearance, Han advocates a return to 18th century's opacity and theatre. "The world of the 18th century was still a theatre. It was full of scenes, masques and figures . . . There was no crucial difference between streetwear and theatrical costumes" (Han, 2012, p. 70). The infatuation with theatre was so big that people started playing with appearances and scenic illusions by dressing up extravagantly. Han seems to be oblivious to the fact that only the minority of affluent citizens could afford to stylize their clothes according to theatrical conventions; the majority could not even afford a theatre ticket. Moreover, the claim that everything is screened is a rather bold assertion: while persons on welfare benefit in Germany have their online activity screened four times a year for undeclared additional revenues, such as eBay sales (Gebert, 2014, paragraph 2), the Bundestag administration refuses to disclose to which pressure groups roughly 1000 entrance passes to the Bundestag have been issued via a legal loophole which was unknown to the public until Abgeordnetenwatch discovered and reported about it (Reyer, 2015). Nevertheless, Han asks the right questions but answers them too cursory. That does not do them justice but they are justified. 


\subsection{Firefighters and Anarchists: On the Inadequacy of Altruism}

Han is not the only one who advocates a return to opacity. Diametrically opposed to Mann's idea of challenging surveillance is the Camover game, initiated by German activists. After several incidents in Germany in 2013 that sparked a discussion about an increase in the use of surveillance cameras, a mobilization video appeared (Camover, 2013) in which several masked men walk around streets, subways, and subway stations and destroy CCTV cameras. This video was the starting shot to the reality-game Camover, initiated by a loose affiliation of activists. In order to protest against increasing surveillance, activists invited people to form groups, destroy surveillance cameras and post the number of demolished cameras on well-known leftist forums. The group with the largest number of destroyed cameras was awarded a place in the first line of a demonstration against the European Police Congress. In an interview with The Guardian, one of the organizers stated that they chose to portray it as a game for they hoped to be able to mobilize otherwise inactive people (Stallwood, 2013, paragraph 6). Apparently, this tactic worked out since their call was echoed in many German cities, but it eventually also spread to America, Finland and Belgium. Moreover, their intervention received international press attention.

Criticism of this intervention was abound; the police initiated criminal investigation procedures concerning public incitement to commit penal offences, and victims complained about the injury of private property. Hülsman, a member of the German Working Group on Data Retention, has pointed out that such forms of protest result in the self-criminalization of opponents of surveillance and might lead to an increase in CCTV cameras (Wrusch, 2013, paragraph 9). This intervention is symptomatic of another way in which activists and philosophers deal with vision. The Camover activists constructed vision in purely negative terms. They believe vision to be inherently dangerous since it is a governmental mechanism of repression. 
Therefore and according to this logic, it is imperative to reestablish opacity by blinding the state. However, just like CCTV cameras are an ex post facto solution, so is their destruction. Oscar Wilde, discussing the problem of poverty, famously remarked that

[t] he emotions of man are stirred more quickly than man's intelligence . . . it is much more easy to have sympathy with suffering than it is to have sympathy with thought . . . they [the majority of the people] very seriously and very sentimentally set themselves to the task of remedying the evils that they see. But their remedies do not cure the disease: they merely prolong it. Indeed, their remedies are part of the disease (Wilde, 1891/1966, p. 1079).

Concerning poverty, this boils down to the insight that it is immoral to use private property to alleviate problems caused by the existence of private property. Instead, one should rather try to reconstruct society on such a basis that poverty will be impossible. The Camover intervention is exemplary of Wilde's critique. Just like firefighters, activists rushed to cameras whenever they saw one. Since it spread to other countries, it might have been a good PR stunt and it could be argued that it expressed a widely shared wish for less surveillance. However, it was bound to remain a PR stunt. The activists were combatting the symptoms of surveillance, rather than its roots. The information asymmetry will not be changed by a few missing CCTV cameras nor will the hierarchy of gazes.

\subsection{Discussion}

The sustainability reports and the general drift in the Obama administration exemplify a conception of transparency closely modeled on the Panopticon. Information is disseminated from a clear vantage point. The empowered 
overseer decides what is made transparent, how it is made transparent, and is even defining the very term transparency (Herrmann, 2013, p. 139). It is a form of transparency that leaves the information asymmetry and therefore also the power asymmetry untouched. While politicians and companies often evoke transparency, they do so on their own terms. As a result, shaped by the logic of surveillance, transparency becomes the site for the reproduction of the logic of surveillance. Boiral developed a convincing argument and pointed out that the sustainability reports are mere simulacra, that is, information without a real referent in objective reality. The Associated Press analysis indicates that Obama's commitment to transparency is mere lip service. Thus, in order to prevent transparency from sliding into the realm of hyperreality, it needs to be constructed differently.

Surveillance and transparency have the same aim, to restrict immoral behavior by exposing it to increased visibility. Bessire convincingly argued that the current discourse on transparency shares many similarities to Foucault's panopticism, even though her negative evaluation oversimplifies matters. Mann's idea of challenging surveillance by establishing total transparency in the form of sousveillance is certainly compelling but nevertheless utopic. Utopic, because it does not require a mental change but relies solely on the use of modern technologies. He declares the Internet and the grassroots culture to be good by nature and shunts evil onto artificiality. However, the transformative power of the Internet and of grassroots culture to change society for the better cannot be taken for granted. The presence of sousveillance can be used for slander and calumny as well as for emancipatory ends. Moreover, the architecture of surveillance could impose itself on sousveillance. Official institutions and authorities can use information gathered via sousveillance and use it for their own ends. The Belarus author and researcher Morozov is highly critical of what he calls Technological Solutionism, that is, the belief that any problem can be fixed 
by technology. In a short talk, he claims that we often confuse the intended use of technology with its actual use. Technology can be helpful in solving problems but it can also be detrimental. For example, social networks helped organizing democratic protests during the Arab Spring. However, they were also used as a repressive tool of the government for the subsequent arrest of protestors by uploading pictures of protestors and asking the public to identify them (Morozov, 2011).

While WikiLeaks exhibits many features that also characterize Mann's idea, such as a reversal of the mono-directionality of information dissemination, there is one major difference. Mann indiscriminately records and disseminates data whereas WikiLeaks' modus operandi is more selective. Assange's aim is to throttle conspiratorial regimes by attacking their communication and therefore rendering them less effective (Fenster, 2012, pp. 774-781). While it can be argued that the disclosure of state department cables is akin to firing indiscriminately, it is a logical move according to Assange's rationale. Moreover, not all documents sent to WikiLeaks are actually published. Next to going through procedures establishing their veracity, they also have to be relevant enough to be published. Thus, WikiLeaks has specific aims and selects its material accordingly.

Assange and Mann think the world to be too opaque and try to remedy this with increased transparency whereas Han, Bessire and the Camover activists think the world to be too transparent and advocate a return to opacity. Although deciding who is right would exceed the scope of this chapter, a preliminary answer can be given.

The Camover intervention highlighted the difficulty of finding a way back to opacity. In a world of ever-increasing visibility, transparency is not anymore restricted to politics or economics but has become a societal 
phenomenon ranging from architecture to televised reality shows. A return to opacity can therefore not be focused exclusively on politics and economy. Moreover, the structure of that return is an unsolved issue, just like its feasibility and desirability. WikiLeaks' disclosures represent a completely new way of transparency: they radicalize the meaning as well as the extent of transparency. The heated reactions show that it not only violated long established boundaries but also that it was successful and that WikiLeaks was perceived as a considerable threat. If knowledge creates power, making everything public erases established information asymmetries and therefore power relations, yet new power relations can impose themselves.

Surveillance is inherently asymmetrical because only some people are allowed to watch and record and only some have access to the centralized data repository. Trying to contain surveillance, as the Camover activists did, is only a pacifier since surveillance information is collected and exchanged by agents over which individuals have very little control (Mann, 2003, p. 333).

WikiLeaks organizes individual entities, the whistleblowers and the interested public, around a single platform. However, this centralization of grassroots movements is not inherently good. A Thai parliamentary committee set up a website called protecttheking.net. In order to show their loyalty to the king, Thais are asked to inform on anyone who criticizes or insults the king. Since penalties for lèse-majesté are draconic in Thailand, this website is a powerful tool to crush down protest. In its first 24 hours of operation, 4814 websites criticizing the political system have been shut down by the government, as the $B B C$ reports ("Thai Website", 2009, paragraph 8). Rather than disclosing information that is harmful for governments, whistleblowers disclose information that is beneficial for the government - and harmful for its critics. Thus, platforms like WikiLeaks do not by default challenge surveillance. Sometimes, they establish transparency just to widen the net of surveillance. 


\subsection{Conclusion}

This paper shed light on the interplay of surveillance and transparency and pointed out possible dangers. While each activist constructs vision and visibility in a different way, they are united in their inclusive approach. Whereas panoptic transparency reduces the individual to a passive receiver of information, all other interventions included participation of the general public. A concomitant of that inclusive nature is an increasing decentralization of vision and visibility and a rejection of mono-directionality. This decentralization was greatly helped by the Internet. Nevertheless, a too deterministic reading of the positive impact of modern technology on the process of democratization is an oversimplification.

Interestingly enough, companies, governments and the anarchist Camover activists have one thing in common: the rejection of increased visibility and a negative concept of vision; all three apparently prefer opacity. The activists are united in their inclusive construction (or destruction) of vision, but this is as far as their common features go. The Camover activists want to decrease their own visibility whereas Mann pushes his own visibility to the maximum and indiscriminately discloses information. WikiLeaks takes a different approach and tries to increase governmental visibility by selectively leaking classified documents. While WikiLeaks and Mann have highlighted ways to challenge surveillance and expand transparency, they house considerable dangers. Transparency is more often evoked than defined, and even less well defined are its potential benefits, aside from generalizations, such as market efficiency and accountability.

Before one accepts these dangers as necessary evil, a closer investigation of the benefits of transparency is needed. Rather than outright endorsement or outright rejection, research into what actually makes vision 
so dangerous is needed. And only if that is known can a substantiated discussion be held about transparency, surveillance, the construction of vision and its artifacts. Moreover, due to the increased digitalization, surveillance has taken different forms compared to Foucault's Panopticon. Therefore, research into post-modern forms of surveillance and coercion is needed in order to study in how far the construction of vision by activists is different or similar to governmental surveillance. At any rate, the German TV show Die Anstalt was quite right in pointing out that as long as we still use Facebook rather than Diaspora, Apple rather than Linux, and Google rather than Startpage, complaining about surveillance is hypocrisy (Die Anstalt, 2015). 